The University of San Francisco

USF Scholarship: a digital repository@ Gleeson Library |

Geschke Center

Psychology

College of Arts and Sciences

2005

\title{
The Influence of Sexual Assault and Fear of Crime on Judgments of Rational Discrimination
}

Saera R. Khan

University of San Francisco, srkhan@usfca.edu

Christina A. Byrne

Kay Livesay

Follow this and additional works at: http://repository.usfca.edu/psyc

Part of the Psychology Commons

\section{Recommended Citation}

Khan, Saera R., Christina A. Byrne, and Kay Livesay. 2005. "The Influence of Sexual Assault and Fear of Crime on Judgments of Rational Discrimination." Journal of Social \& Clinical Psychology 24, no. 7: 963-980. DOI: 10.1521/jscp.2005.24.7.963

This Article is brought to you for free and open access by the College of Arts and Sciences at USF Scholarship: a digital repository @ Gleeson Library | Geschke Center. It has been accepted for inclusion in Psychology by an authorized administrator of USF Scholarship: a digital repository @ Gleeson

Library | Geschke Center. For more information, please contact repository@usfca.edu. 


\title{
THE INFLUENCE OF SEXUAL ASSAULT AND FEAR OF CRIME ON JUDGMENTS OF RATIONAL DISCRIMINATION
}

\author{
SAERA R. KHAN \\ University of San Francisco \\ CHRISTINA A. BYRNE \\ Western Washington University \\ KAY LIVESAY \\ Linfield College
}

Female undergraduates rated the rationality of using gender stereotypes in several potentially dangerous situations. We tested whether sexual assault history and fear of crime moderated perceptions of the use of gender stereotypes in public and private settings. Primary results revealed differences in ratings among victims and nonvictims of sexual assault as a function of type of setting. Additionally, fear of crime increased ratings of rationality in nighttime public situations. The implications of these results are discussed in the context of the "rational discrimination" phenomenon (Khan \& Lambert, 2001).

Although social psychologists have extensively studied prejudice and stereotyping over the past 50 years, a debate that began in philosophy (see Levin, 1991; Cox, 1993; Pojman, 1993; Thomas, 1992) has renewed interest in the relation between rationality and discrimination (e.g., Zawadzki, 1948). This debate moved to the national spotlight when social critic Dinesh D'Souza provocatively accused liberals of perceiving many behaviors as racist when in fact these behaviors reflected rational thinking. In particular, some discriminatory behaviors need not be linked to prejudicial or negative group attitudes at all (D'Souza, 1995). According to D'Souza, the discriminatory act of cabdrivers refusing

Correspondence concerning this article should be addressed to Saera R. Khan, Department of Psychology, University of San Francisco, 2130 Fulton St., San Francisco, CA 94117. E-mail: srkhan@usfca.edu. 
Black fares is the rational product of statistical risk assessment. ${ }^{1}$ D'Souza's arguments have not gone uncriticized (see Loury, 1996). Nevertheless, the perceived relationship between rationality and prejudice has been an understudied phenomenon in social psychology (but see Khan \& Lambert, 2001).

\section{PREVIOUS STUDY}

Several theories can be used to predict if prejudicial attitudes influence whether discrimination is perceived as rational. For example, the "scapegoat" theory of prejudice describes how perceivers often view prejudicial attitudes and behaviors as rational responses toward outgroup members despite the absence of indisputable evidence supporting their negative characterization, (Janoff-Bulman, Timko, \& Carli, 1985; Wagstaff, 1982; Allport, 1954; Zawadzki, 1948). According to Allport (1954), this rationalization conceals perceivers' aversion or hostility to the target. In contrast, the "well-earned reputation" theory argues that groups are treated on the basis of the reputation they have earned (Lerner, 1980; Lerner \& Grant, 1990; Zawadzki, 1948). Therefore, negative treatment or discrimination is deserved. Of course the reputation itself may be tainted with irrelevant factors such as attitudes toward the outgroup. In addition, perceivers may choose to selectively focus on analytical information to bolster a pre-existing judgment. Finally, another theory of prejudice represents a "convergence" between the scapegoat and the well-earned reputation theories (Zawadzki, 1948; Ichheiser, 1949). This convergence theory suggests that both groups in question are responsible, in part, for the discriminatory behavior. According to Zawadzki, "..Prejudice is a result of an interaction (more especially, conflict) of both groups and the characteristics of both groups must be involved in its explanation" (p. 133). In this case, Zawadzki does not specify the extent to which each group is responsible for the resulting conflict. Instead, he cautions that subjective factors, such as prejudicial attitudes, most likely outweigh objective ones.

\section{PRESENT STUDY}

Thus far, discussions of rational discrimination have primarily centered on ethnic or racial intergroup relations. To our knowledge, no one has

\footnotetext{
1. Prejudice is defined here as one's affective or emotional response to members of a particular social group.
} 
theoretically or empirically explored the relation between rationality and prejudice in other group domains such as gender. Examining gender discrimination is important because how people judge discrimination considered relatively more socially acceptable remains unclear. Gender discrimination may be perceived differently from the type of discrimination depicted in D'Souza's cabdriver example not only because of its widespread practice but also because perceivers may see similarities between themselves and the discriminator. For example, many people see it is as prudent or rational when a woman exercises caution around unfamiliar men (Khan, 2003). If a woman does not allow a male stranger to use the phone or if she crosses the street at night to avoid a lone male, it does not result in the same protest as race-based discrimination. Discrimination against males is not seen as reprehensible to society at large since many men advocate this practice and do not seem to suffer seriously adverse consequences. ${ }^{2}$ In this case, some may argue that acts of gender discrimination can be explained by the well-deserved reputation theory in that people may resort to negative personal experiences as their defense.

Examining gender discrimination of this sort allows an examination of whether personal experience influences judgments of rationality. Several theories have been proposed to explain how past behavior or experience influences beliefs about present and future behaviors (for a test of these models, see Albarracin \& Wyer, 2000). Although this study does not test the viability of each model, any of these models provides support for the notion that past experience influences judgments and behavior. We are particularly interested in how past experience might reaffirm or increase the tendency to approve of certain forms of discrimination.

In this study, personal experience is primarily conceptualized in two ways: personal fear of crime, and sexual assault history. We assume that although both of these constructs may be related, they are distinct from each other and will lead to different predictions depending on the type of setting in which the discrimination takes place. We assume that even if women are not victims of crimes, their fear of crime influences the extent to which they assess situations as dangerous or not. Although fear of crime is not as strong of an "experience" as is sexual assault, women with relatively higher levels of fear of crime might perceive a greater similarity between their own behavior and that of the woman depicted

2. Although it is important to understand people's responses to socially normative discrimination, it is beyond the intent or scope of this article to debate why this difference in racial and gender scenarios exists. Moreover, addressing whether or not our participants' judgments are appropriate is not the aim of this article. 
in the scenarios in the present study (Davis, Conklin, Smith, \& Luce, 1996). Dissonance theory suggests that women who score high in the fear of crime are likely to rate discriminatory behavior arising out of fear as rational and not reflective of prejudice.

Victims of personal crimes might be more sensitized to aspects of a situation reminding them of their prior experience. Many sexual assault victims experience increased fear and anxiety that may continue for months or years following the assault (Calhoun, Atkeson, \& Resick, 1982; Kilpatrick, Resick, \& Veronen, 1981; Resick, Calhoun, Atkeson, \& Ellis, 1981). Fear and effortful avoidance of assault-related stimuli, possibly including assailant's demographic features (e.g., age, sex, or race) or particular locations, is not uncommon following criminal victimization (Foa, Riggs, \& Gershuny, 1995; Kilpatrick, Veronen, \& Best, 1985).

The setting in which the discrimination takes place will determine if personal experience is seen as relevant and used as a guide for whether the behavior is judged as rational or not. For example, because most sexual assaults take place in private settings such as a home or dormitory room (BJS, 2000, 2001), we predict that sexual assault victims compared to nonvictims will be more attuned to potential dangers in private settings. Therefore, sexual assault victims will regard the use of gender stereotypes in potentially dangerous situations as more rational in a private setting than would women without a sexual assault history. Fear of crime, on the other hand, is most likely salient when in public as opposed to private settings and therefore will predict people's judgments of rationality for situations that take place in public settings. The key ways in which the scenarios are designed to maximize differences in judgments by victim status and fear of crime are further discussed in the Method section.

This study examines whether personal experience influences the extent to which people view gender-based discrimination as rational or not. We predict that the type of setting (public vs. private) will influence the extent to which types of personal experiences will be used as a basis for judgment. In particular, we predict that victims of sexual assault compared to nonvictims will more likely view the discrimination as rational in a private setting. Also, we predict that participant's fear of crime will be used as a guide for judgment of discrimination in a public setting as opposed to the private setting. Most importantly, we do not expect results to replicate across different scenarios. That is, different scenarios were constructed precisely to test whether fear of crime and sexual assault history differentially predicts responses to scenarios. In addition to the public and private setting scenarios, we included a scenario where the interaction takes place in a semi-private setting. This scenario was included for exploratory reasons as we did not have a clear idea of how sexual assault victims or people high in fear of crime would 
respond. Nevertheless, we thought it would be useful to see if personal experiences are used as a guide for judgments in settings irrelevant to their experiences. In the same vein, we also included a racial discrimination scenario to examine the generalizability of judgments to other groups. Furthermore, this scenario serves as a control in that group equivalence on ratings of rationality in one scenario for all participants can be established. The relation between prejudicial attitudes and ratings of rationality was also assessed so that we could explore if there are differences in how people link prejudice with discrimination.

\section{METHOD}

\section{PARTICIPANTS}

A total of 138 female undergraduate students participated in this study in return for partial fulfillment of a course credit.

\section{MATERIALS AND PROCEDURE}

A female experimenter administered packets to small groups of participants. Participants were assured of their anonymity and did not write any identifying information on the packets. The packets contained two parts: (a) gender- and race-based scenarios followed by questions evaluating the young woman and the cabdriver, and (b) questionnaires assessing fear of crime, and personal trauma history. After completing the packet, participants were thoroughly debriefed and provided with information for campus and community resources in the event that they experienced psychological distress after completing the study. To our knowledge, no participants appeared to be distressed or sought help following their involvement in the study.

\section{Rational Discrimination Study Stimulus Materials}

The following is an excerpt of the instructions received by participants:

In everyday life, we often have the opportunity to observe the decisions that other people make. Sometimes their decisions seem like "good decisions" and represent the best course of action they could have taken, but in other cases their decisions seem like "bad decisions" and do not represent the best course of action.

The order of scenarios was counterbalanced so that half the subjects read and evaluated the cabdriver scenario first and the female scenario second (order 1), whereas for order 2 participants read the scenarios in reverse order. In the cabdriver scenario, John does not pick up a young 
Black male out of safety concerns (for more details on the scenario, see Khan \& Lambert, 2001). Afterward, participants rated the driver with respect to the rationality of his decision and their perception of his personality. Because the primary interest of this article is to examine the role of personal experience in judging the use of stereotypes by others, we will report on the female scenario followed by the cabdriver scenario.

\section{Gender-Based Discrimination Scenarios}

Participants read one of three possible scenarios about Ann, a female who is close in age to most undergraduate students. Each scenario was constructed to realistically represent a potentially dangerous situation that a woman might encounter. The scenarios differ from each other in many ways but in particular, we varied the scenarios so that they ranged along a private to a public continuum. The most private situation takes place in her dormitory room. In the semi-private situation, Ann is in an elevator. In the public situation, Ann is on a street. We hypothesized that the type of setting would provide different cues for danger depending on participants' personal experience with sexual assault or fear of crime. In particular, women with a sexual assault history might be sensitized to dangers related to private settings than women who have not experienced sexual assault. Participants who report high fear of crime might be more cautious in a public rather than in a private setting, compared to participants with low fear in crime. Although it is relatively rare to hear about crimes taking place in semi-private scenarios and it is difficult to predict what types of cues will sensitize participants to potential danger in this scenario, it was included for exploratory reasons. Primary analyses focused on the public and private scenarios only. ${ }^{3}$

Private Scenario. Ann had just moved to Denver to start college. She was excited about college and eager to meet many new and interesting people at her school. On Wednesday, April 18th at approximately 10 p.m., Ann was studying in her dorm room when she heard a knock on the door.

Ann got up to answer her door. When she opened her door, she noticed that it was a guy who looked familiar to her. He asked if he could use her telephone because the one in his room was not working properly. Ann made an excuse that she was waiting for a long-distance phone call from her mother and suggested that he use the phone in the lobby downstairs. When he left, Ann thought to herself, "even though he might think that I was rude, it's better to be safe than sorry."

3. Results from the semi-private condition showed floor effects; therefore discussion of these results is explored in the General Discussion. 
Semi-private Scenario. Ann had just moved to Boston after graduating from college. She looked forward to seeing the new and exciting sights she had heard so much about. On Wednesday, April 18th at approximately 3 p.m., Ann was waiting for the elevator to take her to an appointment on the fourth floor of the building. While waiting, Ann mentally went over the list of errands she needed to do after her appointment.

When the elevator door opened, Ann noticed that there was only one man in the elevator. Ann immediately turned around and waited for the next elevator. Ann thought to herself "I'd rather be a few minutes late for my appointment and be safe, than be sorry."

Public Scenario. Ann Johnson had just graduated from college and started her new job in Denver. She was excited about living in a new place and seeing the new sights she had heard so much about. On Wednesday, April 18th, Ann had to work until 8 p.m. to help her boss meet a project deadline.

The bus station was only a few blocks from her office. As she walked down the street, Ann noticed a man on the same side of the street who was about to pass her. Ann crossed the street before she encountered this person. As Ann crossed the street, she thought to herself, "even though he might think that I was rude, it's better to be safe than sorry."

\section{Assessment of Dependent Variables}

Quality of Decision. After reading each of the scenarios, participants assessed the quality of the decision and their impression of that person. Participants rated the decision along a scale ranging from -5 (a very bad decision) to +5 (a very good decision). Using a scale ranging from 0 (not at all) to 10 (very much so), they also answered six questions concerning the perceived rationality of the decision ("To what extent do you see his/her behavior as appropriate for the given situation?" "To what extent do you view the decision as rational?" "To what extent do you see Ann as thinking logically in this situation?" "To what extent do you sympathize with Ann's predicament?" "Do you think that Ann felt any anxiety or guilt before or after she made her decision?" How often do you think such events really occur?" )

Personality Judgments. Participants answered questions pertaining to their overall impressions of Ann along a scale ranging from -5 (very unfavorable) to +5 (very favorable). Using a scale ranging from 0 (not at all) to 10 (extremely), participants then rated her with respect to five general personality traits (rational, intelligent, hostile, likable, and cautious).

Ratings of Prejudice. Using the same 0-10 scale, participants rated the extent to which they thought Ann had a negative attitude toward men. 


\section{Ratings of Personal Behavior}

Participants also reported the extent to which they behaved similarly to Ann using a 0 (never) to 10 scale (very often). "Please indicate how often you behaved similarly to Ann in this scenario? That is, were you cautious or afraid of someone because they were male?"

\section{Assessment of Fear of Crime and Sexual Assault History}

Fear of Crime. Fear of crime was assessed using a modified version of the fear of crime questionnaire utilized in the Fear of Crime in America Survey (Ferraro, 1996). Respondents used a ten-point Likert-type scale to indicate their level of fear regarding 12 different crimes. Crimes included property crimes, such as "someone breaking into your home while you are away" and "having your car stolen," and personal crimes, such as "being sexually harassed," "being raped or sexually assaulted," and "being attacked by someone with a weapon." Possible responses ranged from 1 (not at all afraid) to 10 (very afraid).

Sexual Assault History. Sexual assault history was obtained in two ways. First, after completing the Fear of Crime measure, participants were asked to indicate whether or not they had actually experienced each of the crimes listed. Thus, women were asked directly if they had ever been raped or sexually assaulted. Second, participants completed the Traumatic Stress Survey (TSS; Gallagher, Riggs, Byrne, \& Weathers, 1998), a self-report measure used to assess the occurrence of highly stressful life events. The TSS includes 20 stressful events, including behaviorally specific descriptions of sexual assault such as "someone, including a friend, partner, or family member, used physical force or threat of physical force to make you have sexual intercourse with them when you did not want to." Respondents indicated which of the stressful events on the list they experienced.

\section{RESULTS}

\section{PRELIMINARY ANALYSES}

Sufficient variability in sexual assault history was obtained. As expected from prior data on sexual assault prevalence, (BJS, 2000), $62 \%$ of the participants $(N=85)$ did not identify as victims of sexual assault and $38 \%$ of the participants $(N=53)$ reported having been victims of sexual assault in the Traumatic Stress Survey questionnaire. ${ }^{4}$ An analysis was first con-

4. Of these 53 participants, 25 responded "yes" to the question "Have you ever been raped or sexually assaulted?" Twenty-four of these individuals indicated that their attacker was male and 20 reported knowing their attacker. The 28 other participants indicated sexual assault on the TSS questionnaire. These numbers are consistent with prior research indicating that many women do not label their experiences with forced, unwanted sexual intercourse as rape (BJS, 2000; Koss, 1988, 1992). 
ducted to assess whether group differences existed between sexual assault victims and nonvictims in fear of crime. The distribution of scores revealed that fear of crime was normally distributed across both groups. ${ }^{5}$ A one-way analysis of variance revealed no difference between groups on fear of crime, $F(1,135)=3.36, p>.05$. This finding is important because it suggests that victims and nonvictims have equivalent concerns about crime.

A principal factor analysis with a direct oblimin rotation was conducted to create an index of perceived rationality across the public and private scenarios. Questions regarding the quality of Ann's decision were included in this analysis. The analysis revealed two factors with eigenvalues greater than 1 . However, the scree plot revealed a large decline in eigenvalues between the first and second factors (3.97 to 1.14). On the basis of these results, an index was created only out of the first factor, which captured $57 \%$ of the variance and was comprised of five items representing the rationality of Ann's decision (i.e., appraisal of her decision, appropriate, rational, logical, sympathize). From this point on in the article, analyses examining rationality of decision are based on this index (alpha $=.95)$.

A second principal factor analysis with a direct oblimin rotation was conducted to create an index for ratings of Ann's personality across scenarios. Here, two factors also had eigenvalues greater than 1. Similarly, the scree plot revealed a large decline between the first and second factors (eigenvalues $=3.60$ vs. 1.10). Therefore a composite was created only out of the first factor. The first factor accounted for $51 \%$ of the variance and represented judgments of Ann's personality with respect to rationality. A composite of these three items (overall impression, intelligence, and rationality) was created, alpha $=.93$. From this point on, analyses involving Ann's personality are based on this index.

\section{PRIMARY ANALYSES}

A hierarchical regression analysis was used to analyze the rationality of the decision as a function of the setting of the encounter (public vs. private), assault history, and fear of crime. Because sexual assaults generally occur in private settings, we expected to find that victims would rate the decision as more rational in this setting compared to the public set-

5. One participant was dropped from the analysis for failure to complete the Fear of Crime scale. Regression diagnostics to examine influential outliers with high leverage revealed two extreme cases in the cabdriver scenario but not in the female scenario. These two cases were dropped prior to cabdriver analyses. 
ting. We also predicted that fear of crime would influence participants' responses in the public scenario so that higher levels of fear of crime would be associated with higher ratings of rationality. ${ }^{6}$ Hierarchical regression revealed two significant two-way interactions, $\left(\left[R^{2}=.16, F(3\right.\right.$, $87)=2.53, p<.01$, for step $2, R^{2}$ change from main effects model $\left.=.114\right]$ ). The first interaction involved assault history by type of setting. The second one involved fear of crime and type of setting. The three-way interaction was not significant, $R^{2}$ change $=.03, p=.10$. Each effect will be discussed separately below. Hierarchical regression analyses involving the same three independent variables with ratings of Ann's personality paralleled these results with two two way interactions involving the same variables, $\left(\left[R^{2}=.16, F(3,87)=2.70, p<.01\right.\right.$, for step $2, R^{2}$ change from main effects model $=.116])$. These ratings of personality will be presented in conjunction with the ratings of the decision.

Ratings of Rationality and Personality by Assault History and Type of Setting. The first two way interaction involved assault history and type of setting on ratings of rationality of decision, $([\beta=.99, S E=.42, t(88)=2.34, p<$ $.02])$. As can be seen in Table 1, the predicted pattern was confirmed. Victims of sexual assault rated her decision as more rational in the private setting compared to nonvictims $(M=8.09$ vs. 6.95$)$. That is, assault victims viewed her decision not to let a male use her phone as more rational than did nonvictims. A simple effects test reveals this difference to be marginally significant, $F(1,48)=3.66, p=.06$. Interestingly, the pattern of ratings in the public setting (i.e., crossing the street) are reversed so that nonvictims rated her decision as more rational than did victims, but the difference is not significant, $F(1,43)=2.22, p=.14$. Importantly, ratings of Ann's personality mirrored these results. There was a significant two-way interaction involving assault history and type of setting, ( $[\beta=$ $.80, S E=.34, t(88)=2.35, p<.02)$. In this case as well, victims rated her personality as relatively more rational in the private condition $(M=6.39$, $S D=1.63)$ than did nonvictims $(M=5.64, S D=1.66)$. A simple effects test revealed the difference to be nonsignificant, $F(1,48)=2.33, p=.13$. Nonvictims rated her personality as more rational in the public setting $(M=6.25, S D=1.25)$ compared to victims $(M=5.39, S D=2.02)$ and this difference was not significant, $F(1,43)=2.96, p=.09$. A greater sample size would most likely yield significant simple effects tests; nevertheless the patterns obtained are consistent with our predictions. Taken together as a whole, these two sets of significant interactions indicate that

\footnotetext{
6. Because preliminary analyses revealed that order did not influence ratings on its own or interact with other variables it is not mentioned in the discussion of the results.
} 
TABLE 1. Means and Standard Deviations for Ratings of Rationality of Decision by Assault History

\begin{tabular}{lcr}
\hline & \multicolumn{2}{c}{ Assault History } \\
\cline { 2 - 3 } Scenario & \multicolumn{1}{c}{ Victims } & Nonvictims \\
\hline Private & $8.09(S D=1.48)$ & $6.95(S D=2.32)$ \\
Public & $6.84(S D=2.31)$ & $7.76(S D=1.72)$ \\
Cab driver (control) & $3.28(S D=1.73)$ & $3.61(S D=1.76)$ \\
Semi-private & $3.40(S D=2.40)$ & $3.79(S D=1.60)$ \\
\hline
\end{tabular}

sexual assault history and type of setting influenced participants' judgments of rationality.

Importantly, our findings were confirmed when we compared the effects of the private and public scenarios with the control scenario depicting a cabdriver. Regardless of whether participants were assigned to read the public or private scenario, their ratings of the rationality for the cabdriver did not vary as a function of prior assault history, $F(2,135)<$ $1.0, p>.10$. This finding is important for two reasons. First, it shows that the differences between victims and nonvictims' ratings of rationality do not generalize across irrelevant settings. Second, this finding demonstrates that the groups were equivalent on ratings of rationality prior to their assignment to story conditions. Thus, any differences in ratings of rationality found in the gender scenarios cannot be attributed to pre-existing and unaccounted for differences among our participants.

Correlation between Prejudice and Ratings of Rationality. Correlational analyses were conducted to examine whether prior experience of sexual assault increased justifications of discriminatory behavior in public and private settings in the gender scenarios. It stands to reason that the more participants view a decision as rational, the less they view it as prejudicial. As expected when the setting was private, ratings of rationality and prejudice correlated $r=-.74, p<.001$ among victims, but not among nonvictims, $r=-.27, p=.16,{ }^{7} \mathrm{Z}$ for the difference $=2.12, p<.01$. (see Table 2). In contrast, for the public setting, correlational analyses revealed non-significant negative correlations between Ann's rationality and prejudice among victims, $r=-.39, p=.10$, and nonvictims, $r=-.22, p=.31$, Victims appear to justify their ratings of rationality in the private setting. This finding points to a greater incidence of rationalization of discrimi-

7. The -.27 correlation is nonsignificant, suggesting large variability in scores. 
TABLE 2. Correlation Matrix of Rationality of Decision and Prejudice Measures by Setting and Sexual Assault History

\begin{tabular}{lcr}
\hline Scenario & Victims & Nonvictims \\
\hline Private & $-.74^{* *}$ & -.27 \\
Public & -.39 & -.22 \\
Cab Scenario (control) & $-.25^{*}$ & $-.59^{* *}$ \\
\hline
\end{tabular}

Note. ${ }^{*} p<.05 ; * * * .001$.

natory behavior in the exact situation predicted as subjectively dangerous for them. It appears that victims and nonvictims construe the link between prejudice and discrimination differently when it comes to gender-based scenarios. These results will be explored in greater depth in the Discussion.

The relationship between ratings of the cabdriver's rationality and prejudice toward Blacks was also examined. First, the mean rating for the cabdriver's prejudice was fairly high, 7.65. The zero-order correlation between rationality and prejudice was significant $r=-.38, p<.001$. Regardless of victim status, there was a significantly negative correlation between ratings of rationality and prejudice (please refer to Table 4). In this case, the correlation was stronger for nonvictims $(r=-.59)$ than it was for victims $(r=-.25), Z$ for the difference $=1.94, p<.03$.

Ratings of Rationality by Fear of Crime and Type of Setting. The second significant interaction involved fear of crime and type of setting, $([\beta=-.44$, $S E=.21, t(88)=-2.09, p<.04])$. As predicted and shown in Figure 1 , fear of crime positively relates to ratings of rationality in the public but not in the private setting. In the public setting, ratings of rationality of the decision increased across levels of fear of crime whereas in the private condition, fear of crime, played no role in ratings of rationality. This finding is complemented by the ratings of Ann's personality. Ratings of her personality were influenced by fear of crime and type of setting, $([\beta=-0.33, S E=.17, \mathrm{t}$ $(88)=-1.93, p=.06])$. A similar pattern emerges here so that participants relatively higher in fear of crime rated her as a more rational person in the public than in the private setting. Therefore, as predicted, fear of crime plays a significant role in reactions to the decision and Ann but only when the discrimination takes place in a public setting.

\section{DISCUSSION}

Primary results in this study suggest that personal experiences do come into play when judging discriminatory behaviors. In particular, the type 

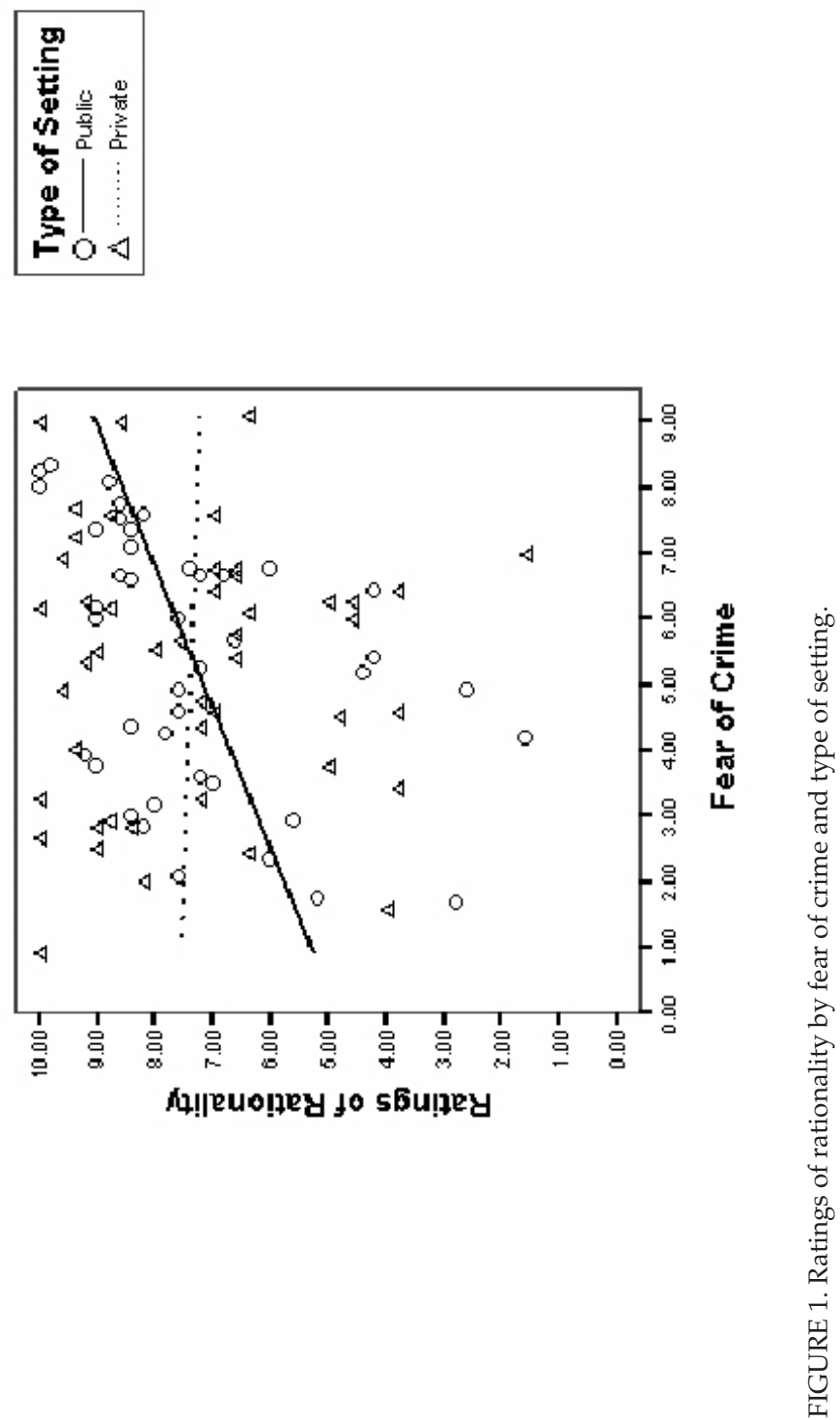
of setting helps determine the type of personal experience used for judgment. Prior to conducting this study, we hypothesized that experience with sexual assault might make women more cautious and more likely to endorse discrimination. However, we understood that certain features such as public and private settings could produce differences in ratings of rationality in the scenarios.

At the outset, one might predict that experiencing sexual assault would predispose victims to constantly practice rational discrimination, especially when it came to gender-based scenarios. However, our findings demonstrate that victims of sexual assault make distinctions among gender- and race-based scenarios. In the cabdriver scenario, both victims and nonvictims responded similarly. In the private setting (i.e., phone) scenario, however, victims gave higher ratings of rationality compared to nonvictims. Interestingly, experience with sexual assault produced the opposite effect in the scenario taking place in the public setting (i.e., street scenario). Nonvictims reacted more strongly to a situation depicted in our culture and media as dangerous, namely the street scenario; in this case, nonvictims gave higher ratings of rationality than did victims. In contrast, the private setting contained common cues that might signal danger for sexual assault victims. For example, in the private setting scenario, the male person is described as somewhat familiar looking. This factor may have alerted victims to be cautious since the majority of sexual assaults against women are perpetrated by someone they know (BJS, 2001). In the college population, approximately $90 \%$ of female sexual assault victims knew the perpetrator (BJS, 2000). Also, the scenario takes place in the undergraduate's dormitory room. Again, many sexual assault victims were attacked at or in their own homes (BJS, $2000,2001)$. Although we cannot know for certain about the settings in which our respondents were assaulted, sexual assault victims may be significantly more wary of these two factors relative to nonvictims.

Fear of crime is an important factor when examining scenarios that take place at night or in public. This result makes sense, as our data suggest that participants' own behavior is guided by their Fear of Crime. It is possible that reading the scenarios first and then completing the fear of crime scale could have primed their fear of crime. However, this is not a great concern given that predicted differences in ratings of rationality were found only in the public setting, and if a priming effect occurred, then it increased the fear for everyone in the public condition. After rating Ann's behavior, participants rated how often they behaved similarly to Ann in this scenario. Fear of crime was positively correlated to self-reported behavior and largely accounted for the relationship between ratings of rationality and prejudice in the public scenario. Fear of crime, however, did not predict participants' reactions to the private scenario. 
Unfortunately, many people do not practice safety behaviors in dormitory settings. Thus, fear of crime was most likely not salient when judging this situation.

For all the scenarios, asking the extent to which they behaved similarly to the woman in the scenario was positively correlated with ratings of rationality. However, personal behavior was challenging to conceptualize as a variable, and thus assessing its impact is difficult. When the pilot study asked participants to rate how often they behaved similarly to Ann, participants gave very low ratings and would state that no one had ever asked to use their phone. In response, we clarified the question by following it with "That is, were you cautious or afraid of someone because they were male?" Unfortunately, this clarifier is equally vague since women encounter men throughout their lives. The proportion of times a woman has behaved cautiously around a male is difficult to quantify in the absence of situational context. Providing a context such as, "when you are alone at night in public" might have produced more accurate and meaningful responses to this question. Nevertheless, ratings of personal behavior provide some insight into how one's own behavior influences judgments of rationality.

For a number of reasons, the elevator scenario did not produce any differences in ratings. Most participants did not view her behavior as rational. As stated earlier, it was difficult for us to predict which cues would be used in a semi-private situation. Furthermore, this particular scenario took place during the day instead of at night like the other two scenarios. An elevator setting in a business office during the day represents an unlikely scenario for a crime. Had we described this situation as an elevator in a city parking garage at night, we may have obtained different results. Also, the setting in which the student respondents completed the questionnaire needs to be considered. The university is located in a small town. Perhaps asking women from large cities to judge this scenario would have produced different results.

Perhaps the most interesting finding is the relation between ratings of rationality and prejudice. D'Souza's (1995, p. 286) view of rational discrimination would suggest that there is no link between rationality and prejudice. That is, discriminatory behavior does not reflect prejudicial thinking but rather a carefully reasoned assessment. This line of thinking is most consistent with the well-deserved reputation theory. In this study, if participants were to exhibit such rational discrimination, there would be a nonsignificant correlation between ratings of rationality and prejudice. In the gender-based scenarios, nonvictims and victims in the public scenario reflected this type of judgment. They gave relatively high ratings of rationality and did not see the behavior as reflective of prejudice. There was no significant correlation between their ratings of 
prejudice and rationality (see Table 2). In contrast, a negative correlation between ratings of prejudice and rationality would fit with D'Souza's description of a "liberal" perspective on discrimination. That is, "liberals" view discriminatory behaviors as irrational and prejudicial. Both victims and nonvictims judged the cabdriver as low in rationality and high in prejudice. In other words, participants viewed his behavior in a manner consistent with the scapegoating theory of prejudice. A negative correlation between ratings of prejudice and rationality was also found for victims in the private setting scenario. Here, just as in the cabdriver scenario, victims showed a strong negative correlation between ratings of rationality and prejudice. However, their mean ratings of rationality and prejudice suggest a different interpretation. Unlike the cabdriver scenario, they gave high ratings for rationality and low ratings of prejudice to the female. This correlation is not explained by D'Souza's description of rational discrimination because a negative relationship exists between rationality and prejudice as opposed to no relationship. In other words, they are not embodying "liberal" discrimination as described by D'Souza. Although it is speculative, dissonance theory would suggest that participants may be engaging in an effort to justify their rational discrimination. In this case, victims may be reflecting an extreme version of the reasoning described in the well-deserved reputation theory.

Our research demonstrates that previous experience such as victimization does not lead to rampant discriminatory behaviors. Sexual assault history only predicts responses to a scenario that most likely resembles the context of a person's victimization experience. The differences in ratings of rationality between the cabdriver's and the female's discriminatory acts suggest that race- and gender-based discriminations are not seen in similar terms. Both victim and nonvictim participants seem to be taking the "target's" perspective into account when deciding if a discriminatory behavior is rational or not. That men generally view this type of discrimination as rational (Khan, 2003), whereas African Americans do not, may account for differences in participants' judgment.

Both the cabdriver and female scenarios represent real-life situations in which instantaneous decisions must be made in the absence of individuating information. Previous social psychological research has shown the influence of cognitive resources (Devine, 1989; LePore \& Brown, 1997; Wittenbrink, Judd, \& Park, 1997), mood (Bodenhausen, Kramer, \& Süsser, 1994; Lambert, Khan, Lickel, \& Fricke, 1997), and terror management (Schimel et al., 1999) on these types of decisions. The present line of research represents a new angle by which we can understand the use of stereotypes and its links with prejudice and discrimina- 
tion. Rational discrimination is akin to racial profiling, a controversial practice employed by some law enforcement officials in judging the potential threat of civilians. Of course, the target and perceiver of these acts of discrimination may have different reactions to these behaviors. Victims of racial profiling have reported feelings of humiliation and despair. At its extreme, racial profiling has played a role in accidental shooting deaths by law enforcement officials (Payne, 2001). Future research should explore understanding perceptions of rational discrimination from both perceivers and targets, so that societal boundaries can be formed to distinguish between what is rational or not and ultimately what is fair and unfair from both perspectives.

\section{REFERENCES}

Albarracin, D., \& Wyer, R.S. (2000). The cognitive impact of past behavior: Influences on beliefs, attitudes, and future behavioral decisions. Journal of Personality and Social Psychology, 79, 5-22.

Allport, G. W. (1954). The nature of prejudice. Reading, MA: Addison-Wesley.

Bodenhausen, G. V., Kramer, G. P., \& Süsser, K. (1994). Happiness and stereotypic thinking in social judgments. Journal of Personality and Social Psychology, 66, 621-632.

Bureau of Justice Statistics (BJS). (2000, December). The sexual victimization of college women (NCJ-182369). Washington, DC: U.S. Department of Justice.

Bureau of Justice Statistics. (2001, January). Criminal victimization in the United States: 1999 (NCJ-184938). Washington, DC: U.S. Department of Justice.

Calhoun, K. S., Atkeson, B. M., \& Resick, P.A. (1982). A longitudinal examination of fear reactions in victims of rape. Journal of Counseling Psychology, 29, 655-661.

Cox, C.B. (1993). On Michael Levin's 'responses to race differences in crime.' Journal of Social Philosophy, 24, 155-162.

Davis, M. H., Conklin, L., Smith, A., \& Luce, C. (1996). Effects of perspective-taking on the cognitive representation of persons: A merging of self and other. Journal of Personality and Social Psychology, 70, 713-726.

Devine, P.G. (1989). Stereotypes and prejudice: Their automatic and controlled components. Journal of Personality and Social Psychology, 56, 5-18.

D'Souza, D. (1995). The end of racism: Principles for a multi-racial society. New York: Free Press.

Ferraro, K. F. (1996). Women's fear of victimization: Shadow of sexual assault? Social Forces, 75, 667-690.

Foa, E. B., Riggs, D. S., \& Gershuny, B. S. (1995). Arousal, numbing, and intrusion: Symptom structure of PTSD following assault. The American Journal of Psychiatry, 152, 116-120.

Ichheiser, G. (1949). Sociopsychological and cultural factors in race relations. American Journal of Sociology, 54, 395-401.

Gallagher, J. G., Riggs, D. S., Byrne, C. A., \& Weathers, F. W. (1998). Female partners' estimations of male veterans' combat-related PTSD severity. Journal of Traumatic Stress, 11, 367-374.

Janoff-Bulman, R., Timko, C., \& Carli, L.L. (1985). Cognitive biases in blaming the victim. Journal of Experimental Social Psychology, 21, 161-177. 
Khan, S. R. (2003). Affective and cognitive factors involved in rational discrimination. Unpublished raw data.

Khan, S.R., \& Lambert, A.J. (2001). Perceptions of "rational discrimination": When do people attempt to justify race-based prejudice? Basic and Applied Social Psychology, 23, 43-54.

Kilpatrick, D. G., Resick, P. A., \& Veronen, L. J. (1981). Effects of a rape experience: A longitudinal study. Journal of Social Issues, 37, 105-122.

Kilpatrick, D. G., Veronen, L. J., \& Best, C. L. (1985). Factors predicting psychological distress among rape victims. In C. R. Figley (Ed.), Trauma and its wake. New York: Brunner/Mazel.

Koss, M. P. (1988). Hidden rape: Sexual aggression and victimization in a national sample of students in higher education. In A. W. Burgess (Ed.), Rape and sexual assault (Vol. 2, pp. 3-25). New York: Garland.

Koss, M. P. (1992). The underdetection of rape: Methodological choices influence incidence estimates. Journal of Social Issues, 48, 61-75.

Lambert, A.J., Khan, S.R., Lickel, B., \& Fricke, K. (1997). Mood and the correction of positive vs. negative stereotypes. Journal of Personality and Social Psychology, 72, 1002-1016.

Lepore, L., \& Brown, R. (1997). Category stereotype activation: Is prejudice inevitable? Journal of Personality and Social Psychology, 72, 275-287.

Lerner, M.J. (1980). The belief in a just world: A fundamental decision. New York: Plenum.

Lerner, M.J., \& Grant, P.R. (1990). The influences of commitment to justice and ethnocentrism on children's allocations of pay. Social Psychological Quarterly, 53, 229-238.

Levin, M. (1991). Responses to race differences in crime. Journal of Social Philosophy, 23, $5-29$.

Loury, G.C. (1996). The end of relativism. In R.C. Monk (Ed.), Taking sides: Clashing views on controversial issues in race and ethnicity (2nd ed., pp. 70-74). Guilford, CT: Dushkin Publishing Group.

Payne, B.K. (2001). Prejudice and perception: The role of automatic and controlled processes in misperceiving a weapon. Journal of Personality and Social Psychology, 81, 181-192.

Pojman, L. (1993). Race and crime: A response to Michael Levin and Laurence Thomas. Journal of Social Philosophy, 24, 152-154.

Resick, P. A., Calhoun, K. S., Atkeson, B. M., \& Ellis, E. M. (1981). Social adjustment in victims of sexual assault. Journal of Consulting and Clinical Psychology, 49, 705-712.

Schimel, J., Simon, L., Greenberg, J., Pyszczynski, T., Solomon, S., Waxmonsky, J., \& Arndt, J. (1999). Stereotypes and terror management: Evidence that mortality salience enhances stereotypic thinking and preferences. Journal of Personality and Social Psychology, 77, 905-926.

Thomas, L. (1992). Statistical badness. Journal of Social Philosophy, 23, 30-41.

Wagstaff, G. (1982). Attitudes to rape: The "just world" strikes again? Bulletin of the British Psychological Society, 35, 277-279.

Wittenbrink, B., Judd, C. M., \& Park, B. (1997). Evidence for racial prejudice at the implicit level and its relationship with questionnaire measures. Journal of Personality and Social Psychology, 72, 262-274.

Zawadzki, B. (1948). Limitations of the scapegoat theory of prejudice. Journal of Abnormal and Social Psychology, 43, 127-141. 
Copyright of Journal of Social \& Clinical Psychology is the property of Guilford Publications Inc.. The copyright in an individual article may be maintained by the author in certain cases. Content may not be copied or emailed to multiple sites or posted to a listserv without the copyright holder's express written permission. However, users may print, download, or email articles for individual use. 